\title{
Arts in Science: 'Painting' Health Allied Senior High School Students' Meaningful Learning Engagement
}

\author{
Buen Euleen V. Lainez, Jamie Marie Reynielle D. Agonoy, Rica Madeleine B. Bargo, \\ Zeth Maverick Y. Chua, Mary Angel Adele B. Dizon, Russel Dustin R. Dolendo, \\ Ivhan Miles S. Yumang, Juland D. Salayo \\ Senior High School-University of Santo Tomas, Manila, Philippines \\ jdsalayo@ust.edu.ph
}

\author{
ARTICLE HISTORY \\ KEYWORDS \\ Arts and science, \\ Arts-based instructional approaches \\ Health allied learning \\ Senior high school learning \\ Role and impact of arts \\ Arts \\ Health

\section{Received : 2021-04-11
Revised :2021-07-07 \\ Received :2021-04-11
Revised :2021-07-07 \\ Accepted : 2021-07-11}

approaches

\begin{abstract}
The education system acknowledges the relevance and impact of arts in exploring students' different skills and competencies. However, most of the learners remain bias on the purpose and essence of art-based activities since most of the strands offered in senior high school are academically designed through the K-12 program, which guides and prepares incoming college students in choosing their career path. Hence, this study attempted to determine the vital role of arts-based instructional approaches to enrich students' learning in one selected catholic Senior High school in Manila, Philippine. Applying a qualitative approach through intensive interviews, 15 Health Allied students participated in this study. Results revealed that arts are highly integrated with the delivery of the different lessons of the involved strand. Moreover, arts proved that they have solid and influential roles in improving students' quality of learning. Furthermore, the impact and relevance of arts as an instructional approach supports the learning process of health allied students. Thus, this research informs and guides the teachers and students on the importance and impact of art as an overlooked field in education that maximizes one's potentials.
\end{abstract}

\section{Introduction}

In continuous reforms to improve the quality of Philippine education, learners' needs and differences are usually at the center of the framework to deliver excellent services and results. Hence, inclusivity, social justice, equity, and emancipation are the heart of arguments to benefit the learners; in the end, it will contribute to the country's goals toward economic progress, global competitiveness, and sustainability. Going back to the classroom setting, which serves as the epicenter of learning and development, teachers do every possible way to improve the instructions to attain such life-long learning. In the most recent development, the Philippine Department of Education (DepEd) has implemented the K to 12 program, which aims to strengthen basic education, make the curriculum relevant to learners, nurture the holistically developed Filipinos, among others (Department of Education, n.d.). To materialize salient features and goals of the program, teachers and students engage themselves in various classroom strategies and approaches, including the value and impact of arts in constructing their instruction and learning quality. In education, it is not novel to integrate arts in executing lessons. Many studies
(Mahgoub, 2015; Kariuki, 2016; Punzalan, 2018) have proven that arts leave a positive impact on students' learning and development. In many cases, arts are not just an approach but an instrument to diminish learning anxiety. Swapp (2016) reported that art education benefits humans to improve selfconfidence, communication skills, cognition, and selfunderstanding.

However, the importance of art in overall learning still faces discriminatory elements because of its nonacademic features like other academically-inclined programs and courses in most academic institutions. To date, many students still equate arts to hobbies; hence, the art-related programs may deem insignificant to their future careers. Worse than that, art is not even considered a stable career. For example, in the study of Ruppert (2006), it was identified that most of the universities do not prioritize the study of arts as programs or as courses. In effect, many students do not consider arts as opportunities in their future careers. This same study also revealed that children from low-income families are less likely to be consistently tangled in art activities than higher-income children (Ruppert, 2006). Contrary to this, adolescent art students significantly accomplished more positive 
developmental outcomes than others who do not pursue art coursework in schools. In comparing arts and non-arts students, art-inclined students were much more optimistic about attending school, leading them to have a more advanced and developed performance in academics (Elpus, 2013).

The positive effect of art engagement encourages students to engage more in extracurricular activities because it helps students enhance their performance in the classroom. Participating in such art-based activities is one of the crucial parts of every student's high school experience. It teaches them skills that cannot be obtained in the usual classroom events. Moreover, engagement with different performing art activities in high school increases the academic attainment of students. Additionally, the study showed a definite relationship between arts education and student outcomes despite the absence of a concrete relationship between art instruction and student outcomes (Henry, 2011). Still, Mahgoub's (2015) study on the importance of the development of art education proved that the arts make a valuable contribution to the comprehensive education of students about academic performance, attitude and behavior, and perceptions on learning. This similar study further asserted the benefits of arts education to fall into three main areas, the child, the teaching and learning environment, and the community. Results of this study concluded that there is a significant difference between students' performance before and after the development of art education curriculum and has therefore been recommended its promotion as an integral part of national development policies; thus, ensuring the training of professors for more effective and holistic participatory teaching methods. Looking into specific studies that highlight the role of arts to health allied learning, Punzalan (2018) indicated that arts are always a relevant part of the human affective experience for communication, expressiveness, imagination, and cultural understanding. This study highlights that visual arts have a wide range of fields; unlike other definite disciplines like humanities, it should extend on some aspects. Visual arts-orientated group in studying art appreciation helps performance comparing the traditional lecture-discussion method of the traditional oriented group. Corollary, visual arts in various learning involve confidence development and learning advantages that encourage students to participate.

Additionally, Pelowski et al. (2017) stated that specific psychology on art interacts well with learning challenges. By having an artistic background with the holistic method of experience, it has been concluded that this affected a person's development, perception, and critical thinking. When creativity is heard, it is almost exclusively involved with artists, but art has been a natural way of men even outside the scientific discipline. The study concluded common characteristics between artists: the sense of independence, resourcefulness, and idealism. Hence, the visual arts can widen a person's visual imagination and result in better learning and understanding.

Furthermore, Singg \& Mull's (2017) paper on color and its effect on information retention, a comparative study on young men and women, stated that color impacted the participants' performance based on their gender. Many college students practically use a white background with black writing, so the researchers conducted an experiment seeking to find out which visual aspect of the material's background had a more impact on the students' learning. They concluded that Newton's Color Theory affected the result wherein the color yellow reported more anxiety levels than blue. It was also concluded that women prefer softer colors such as pastel while men prefer brighter colors such as neon in their information retention. Thus, the color of the information materials influenced the students' performance, and professors must influence influential, positive, and coherent teaching.

On the other hand, Gibson \& Larson (2007) conducted action research to test the students in an elementary school with a decreased experience in the arts to identify the relationship between visual arts and academic achievement. Visual arts such as painting, drawing, and sculpture have been minimized, resulting in a limitation of their full potential. Consequences in school are being dealt with what they taught to students and what they failed to teach. It was evident from the results that children are more well-rounded and enriched with their cognitive, emotional, social, and physical dimensions. With this, a child's development is incomplete, and that many students possess a visual learning style as an increase to one's motivation to learn. Tyler \& Likova (2012) mentioned that art is fundamentally a communicative medium that enhances learning. Learning and art production are connected between multiple sensory motors and higher cognitive mechanisms, enhancing a person's capability to learn in other domains. Experiencing art has a power to one's development that relates to one's cognitive skills. In this study, the researchers concluded the eight Studio Habits of Mind taught in studying visual arts: to observe, envision, express, reflect, engage and persist, stretch and explore, develop craft, and understand. This is demonstrated through the thinking skills and working styles taught in art classes.

Relating to the theatre, Kariuki (2016) revealed that students exposed to theatre-arts integration have improved in academic performance. It further revealed that it helps the students' overall grades as it increased the students' engagement and participation and decreased the sense of stress and class disruption. Students who are taught traditionally are often uninvolved and inconsistent with their work which increases students' lack of interest and frequent absences. The study also showed a significant 
difference between genders when using theatrerelated strategies to teach English. The researcher suggested that females are more suited to processing language arts. In terms of dance education, Carter (2004) aimed to identify its effectiveness to students with intensive training and exposure to this kind of art. A comparison is made between those who do not receive dance instruction and those who focus more on academics, self-concept, overall wellness, and school performance. A significant difference was found between dancers and non-dancers for the said disciplines. Among the group of dancers, a positive effect and improved academic performance were observed. However, more interventions address healthier views of wellness and self-concept compared to the non-dancer group.

Focusing on music as a tool for learning, Thomas (2011) showed the impact of musical performing arts on the academic achievement of black males within the United States. The research revealed that black males were one of the lowest-performing demographic groups in America. The study examined the impact of participating in musical performing arts implemented to 112 black males in eighth grade. The study investigated the relationship between music participation and academic achievement. As the results came out, it showed a strong relationship between music performing arts and academic achievement. Besides, Scripp (2002), in their study on music and learning, showed significant effects of learning between music and academic achievement. It stated that musical ability could assess a person's level of mathematical and language arts fulfillment. Music and education should not exist in isolation and are not exclusively divided into two interdisciplinary learning. It has an impact on social-emotional development, behavioral modification, or reinforcement of therapeutic objectives. "If the arts help define our path to the future, they need to become curriculum partners with other subject disciplines in ways that will allow them to contribute their distinctive richness and complexity to the learning process as a whole" (Burton et al., 1999. p. 511).

Similarly, Cabanac et al.'s (2013) paper on music and academic performance stated that students listening to music while performing academic examinations had been proven to lower the students' stress levels while still having high grades. This is called the Mozart Effect. As the researchers examined this study, they were intrigued whether the students' grades got higher because of listening to music or performing better because they are more gifted or motivated. The current paper established relations between music education and academic performance. It is a connection between music and cognition. The results showed that students with musical courses perform better than those who do not have equal initial achievements. Music students had higher grades in all subjects.

Inoa et al. (2014) provide positive relationships between the arts and academic achievement when correlated to the literature curriculum. Positive associations have been seen in the arts and different variations within the discipline, such as Mathematics and Sciences. The study tested whether there is a significant relationship between student achievement and performing arts in the curriculum. It resulted in students' intercession surpass the control group equivalent in both math and language arts. The researchers concluded that participating in art forms can promote academic achievement among involved students, and it also relates to mathematics and other interventions.

This study is anchored to Schechner's (2003) Performance Theory stated that, as with academic studies, it was found that certain fundamental principles such as presentation of self, restored behavior, and expressive culture incorporated social drama and rituals. It examined the use of theory to the theatre practitioners, including the concept of performativity, which is closely related to postmodernism that sees performance as a social and political material and not only as essentially artistic or theatrical that constitutes power and knowledge (Cavanaugh, 2015). Schechner (2003) also stated that people do performances daily - whether on stages such as theatre, dancing, and music, in particular social situations like rituals, practices, ceremonies, or people's daily lives.

Furthermore, Gardner (1983) claimed that all people have different strengths and weaknesses; and types of intelligence such as verbal-linguistic, logicalmathematical, spatial-visual, bodily-kinesthetic, musical, interpersonal, intrapersonal, naturalist, and existential. The Multiple Intelligence Theory suggested that teaching strategies and other pedagogic tools provide knowledge and skills to students since individuals have different skills and capabilities. In arts-based tasks, the types of intelligence that may apply are: spatial-visual which is about visualizing ideas and design and allowing one to envision and create a concept from his mind; bodily-kinesthetic, which refers to the processing of information and expressions through body movements; musical which pertains to having skills and gaining knowledge through music, its rhythm, tone, melodies, and harmony; interpersonal which refers to the relationship created and related with other people and; intrapersonal that pertains to exploring and expressing one's thoughts and feelings. Gardner also asserted that teachers should apply different educational innovations to create goals and values and focus on one teaching strategy when designing instructions.

The study associated the two theories in the importance of participating in arts-related activities by 
Grade 12 Health Allied students. The researchers examined the role of arts (presentation of self, restored behavior, expressive culture) in the students' learning system. This paper stands that despite all the positive claims that arts can produce positive scholastic performance, arts remain an underrated approach in education because works and professions related to art are often compared to more academically-inclined aspects, which are most likely seen and treated by many as the most superior in all professions and educational aspects. Indeed, the position of arts in the curriculum is still unsettled and misunderstood. With that reality, many countries, especially the Philippines, do not invest in arts because of its questionable and unstable economic advantages. Though many still believe that art activities are essential to the education system, it helps develop an individual, its culture, and personal life physically, socially, and mentally. This present study attempts to further establish the impact of artsrelated activities, not just on students' different art skills but also on the overall learning relevant to preparing themselves for a better future. This present study may also support several claims toward the conversion of STEM into STEAM, where art is integrated into science, technology, engineering, and mathematics programs. While STEM, as a program, is highly acknowledged to contribute to economic progress, Art in Action "best prepares children with the skill they will need to become successful, wellrounded thinkers." Hence, the inclusion of " $A$ " helps learners improve their creativity, collaboration, confidence, cultural awareness and empathy, and critical thinking (Art in Action, 2021).

Further, being art major students, the researchers want to establish the significant and purposeful role of arts in the curriculum and learning system it hones the learners' skills and potentials both academically and practically in life and for their future professions. Hence, this paper examined the impact of arts-based instructions on the Senior High School Health Allied (HA) students. Specifically, this study aimed to determine the following: (a) the common arts-based instructional approaches employed among the Health Allied students, (b) the different health allied lessons which are delivered using arts-based instructional approaches and strategies, (c) the impact and relevance of arts-based instructional approaches to Health Allied students' learning, and (d) challenges encountered by the Health Allied students in engaging with the arts-based instructional approach.

\section{Methods}

\subsection{Research Design}

The researchers used a qualitative method to determine the instructional approaches and impact of arts-based activities on the learning capabilities of HA students. According to Bhandari (2020), qualitative research aims to analyze non-numerical data such as opinions and experiences of people to accumulate information about the problem of the study. This research used phenomenology that aims to determine the respondents' experiences in a phenomenon that allows the researchers to explore the different points of view of the respondents to determine the complexities of phenomena. This aims to provide more specific answers and explanations to the questions of a problem through the respondents' experiences (Khan, 2014). Specifically, this study investigated the participants' association with the arts as classroom learning tools and approaches.

Regardless of the engagement and participation in arts-related extracurricular organizations or the students' point of view, 15 Grade 12 Senior High School Allied students in a catholic university in Manila, the Philippines, participated in this study using the purposive sampling technique. To gather the needed data, the researchers interviewed the participants using the researchers-made open-ended questions that aimed to focus on Health Allied (HA) students' experiences and challenges in arts-based instructional approaches. To observe ethical standards specifically to ensure privacy and safety, the researchers distributed consent forms to the qualified participants based on the criteria created. After the participants' approval, the researchers scheduled the interview according to the availability and convenience of both the interviewers and interviewees via Google Meet, Zoom, and Messenger. During the interview transcription, codes are used, i.e., S1, S2, S3, etc., to further protect their identity.

Employing open-ended questions during the interview, the researchers analyzed and interpreted the data through fair means and with the critical judgment due to the subjectivity of the responses. Being a phenomenology, the analysis focused on exploring thoughts and meaning; therefore, arrangement, observation, and a series of comparisons, differences, and similarities characterized the data analysis. To reduce the amount of raw information, similar answers from the respondents were categorized to identify recurring patterns or constructs necessary for analysis and interpretation. The study objectives, related literature, and framework were instrumental in conducting a thematic analysis to build constructs.

Despite the study's qualitative approach, the researchers used the percentage of responses in presenting the results to summarize responses quickly. As Sandelowski (2001, p. 230) stated:

"As in quantitative research, numbers are used in qualitative research to establish the significance of a research project, to document what is known about a problem, and to describe a sample. Nevertheless, they are also useful for showcasing the labor and complexity of qualitative work and generating meaning from qualitative data; to 
document, verify, and test researcher interpretations or conclusions; and re-present target events and experiences. Although numbers are important in the treatment of qualitative data, qualitative researchers should avoid the counting pitfalls of verbal counting, overcounting, misleading counting, and acontextual counting." (p. 230)

Still, the study used non-numerical data, which resulted in an accumulation of varying opinions and experiences provided by the respondents.

\section{Results and Discussion}

\subsection{Arts-based Classroom Approaches Employed among Health Allied Students}

Interestingly, HA professors highly employed artsbased approaches in delivering their lessons as suggested by the curriculum. More than half of the participants claimed that their teachers across disciplines employed graphics arts and design $(51.11 \%)$. Other approaches include video-editing and visual arts with $13.33 \%$ and $4.45 \%$, respectively. Therefore, most arts-based classroom approaches involved graphic arts and design, such as creating brochures, infographics, and posters mostly done digitally. Also, most of the teachers preferred performing arts like theatre and role-playing or group dramatization. According to the participants, these arts support their learning in the different lessons offered to their strand.

Students also summarized the critical points and keys in their lessons to create this type of output, which helped them learn and understand their topics better individually. While performing arts activities such as dancing, acting in skits and presentations, singing, and song composition given to Health Allied students developed their interpersonal intelligence as this activity promotes collaborative and cooperative learning that involves social and communication skills.

Additionally, other arts-related activities employed in the strand were video making and editing original music videos or short films about the assigned topic or lesson. These also permit the students to engage themselves in a group as the activities themselves require collaborative efforts such as scriptwriting, acting, and editing. The equal distribution of workload in a group helped students improve social skills and strengthened the camaraderie among students. Lastly, the minor artsbased activity given to the students was visual arts that included drawing, sketching, and painting, which helped students visualize their lessons to have an easier understanding and improve learning development among their lessons.

Marshall (2015) mentioned two factors that affect the current curriculum. These are (1) art integration which employs simple illustrations of academic topics resulting in a practical understanding while fostering metacognitive skills, and (2) transdisciplinary that aims to achieve deep integration by creating social and cognitive space. Both factors allow learners to grasp the potential of changing their understanding of academic topics and disciplines and art, inspiring them to create new models in the education system. This study intends to start a conversation that may spark the need for change in the system.

\subsection{Lessons/Topics Employed with Arts-based Instructional Approaches according to the offered subjects/courses}

Data revealed that there are different lessons in the HA Strand that applied arts-based approaches. These are evident in the different subjects in the $2^{\text {nd }}$ term of the SY 2020-2021. Presenting the results using percentage, health science and media and technology $(20.83 \%)$ both shared an equal rate in arts employability in delivering different lessons. The majority of the arts-related activities engaged in health science, particularly on the lessons about anatomy, diseases, and its preventions, body systems, proteins, cells, and figures on anatomical positions were in the form of creating brochures and infographics; while media literacy, programming, and computer software fell under the lessons of media and technology which employed activities such as digital art, animations, broadcasting, and podcasts. The middle range was the lessons under communication and literature, specifically, oral and written communication and historical literature (11.11\%). These lessons employed the activities namely: posters, infographics, video-making and editing, and role-play presentations. The least percentage lesson employed with arts-based activity such as board game-making was mathematics, mainly calculus and statistics with $2.78 \%$.

It mainly focuses on the sciences of the body and the health of a person. It also explained why they prefer art-related activities in these lessons as it generally connected with the medical field and is more inclined in their strand than other subjects' lessons. The arts, in some studies, proved to have a significant improvement on the learning of students in the medical field as arts-related activities, namely: brochures, infographics, and figures on anatomical positions, helped students remember concepts and influence imagination, visualization, creativity, and growth. As a result revealed, lessons under media and technology had the same percentage as the health science subject since both subjects have the concepts, specifically in Medicinal Technology, a medical course, computers are now used on many health procedures. Therefore, this revealed that most of the students engaged in art-related activities by their professors fell on their specialized subject, health science. Hence, they acknowledged that engagement with art-related activities helped them absorb basic concepts and integrate art; digital art, animations, 
broadcasting, and podcasts prove students' creativity using technology.

Parallel to the results, Maclean (2007) stated that incorporating humanities, social sciences, and arts contributed to medical and health practitioners' education. Hence, aesthetic aspects of teaching need to be attended in medicine through unimaginative ways as arts foster a different and unique way of illustrating illnesses and diseases. In the study, numerous artists taught various courses and incorporated art-related projects in medical schools. The survey found that the arts nurture the students' well-being, learning capacity, and relational skills. In conclusion, the broadening of students' understanding of arts beyond K-12 education significantly contributed to improving one's preparation through the field of Health and Medicine.

\subsection{Impact and Relevance of Arts-based Instructional Approaches to the Respondents' Learning}

Data revealed that arts-based approaches showed a relatively high impact on the learning of the respondents. It received $60 \%$ of the students' perception that the arts-based classroom approached positively and recognized its impact as a factor for developing their learning. In comparison, $33.33 \%$ of the respondents believed that arts-related activities negatively impacted their academic performance. Furthermore, $6.67 \%$ of the students recognized artsbased classroom approaches applied in their strand negatively impact their learning and capabilities.

This showed that despite the difference of art to the medical field, the positive impact and objective of art is to improve performativity and develop flexibility of oneself was recognized by the majority of the HA students. "Nakaka-help siya for me kasi parang ang plain lang pag pure text and parang mas madali kang mawawalan ng gana mag aral pero pag may onting arts and colors design ganyan, may visual kang nakikita, parang it motivate you para mag aral," (S11) (Arts can help me to learn because if [materials] are just pure text, it does not motivate me at all. When there is a little bit of creativity and visual aspect to it, I am more motivated to study, S11). Arts-based classroom approaches tend to reach the attention and focus of the students by its visual elements that showed the direct topic of their lessons, i.e., anatomy is easier and more convenient to learn and understand when shown visually, which allowed the HA students to discover themselves personally as visual learners. With this type of classroom approach, students absorb information immediately and accurately since with including art in the discussion, it becomes concise yet still directly on point.

Moreover, these participants believed that artsbased activities affect their learning development and maximized their potentials and flexibility in doing tasks like incorporating creativity, improving experimenting and criticizing skills, and practicing time management within their works. Furthermore, as for these respondents, arts also served as a form of transportation for more accessible communication and transmission of lectures and ideas between the students and the educator and benefitted individually since art finds its way to connect personally. "Art can help you express yourself. You could communicate your ideas easier kasi (because) you translate it to other forms of art" (S10).

Furthermore, the smaller number of respondents believed that arts-based classroom approaches contributed both positive and negative impacts but did not conclude that it affected their learning positively or negatively. They only recognized the functional approach when given and applied to the lessons practically and appropriately. They claimed that art helps in their understanding but is too pressuring since not all students are musically or artistically inclined. These students also found arts-based classroom approaches calming yet experienced difficulty with brainstorming as they could not communicate or release their ideas and thoughts about their lessons and activities. On the contrary, the least percentage of students took the arts-based activities negatively as it consumed much of their time and effort, which they find unnecessary since they cannot distinguish the connection of the art applied in their lessons and believe that art has nothing to do with their strand.

According to the study of De la Croix et al. (2011), medical students values art-based learning in their education because it provides more comprehensive exploration about the non-scientific elements such as the communication and the political, social, emotional, and spiritual aspects of the human experience which contributes in the performance of their examinations, presentations, and placements. Arts-based learning also offers and introduces different skills and opportunities to students, such as creative writing, theater, and action movements shaping their flexibility and well-roundedness. Students who engage in these learning practices can communicate and relate to people with different backgrounds and cultures, which prepares them to face and handle endeavors and situations in their future medical profession.

In terms of the perceived relevance, data showed how relevant arts-based classroom approaches are to the curriculum and learning of HA students. Sixty-six and sixty-seven percent $(66.67 \%)$ of the respondents agreed that arts-based classroom approaches and activities were significant in their field of study and future careers. Furthermore, 20\% considered artsrelated activities irrelevant and useless for their curriculum and field of education. In comparison, $13.33 \%$ stood neutrally in this type of classroom approach if relevant to their field of study. 
This reflected that most HA students perceived arts-based classroom approaches immensely relevant and helpful to their field of study as they may be used in the effective immersion of students in medicine and science such as anatomy. "Art-related activities help me in understanding anatomies, parts of the body. Although it is hard, (but) once I get to draw and color it, I get to visualize it more and understand what its functions are" (S5). Art plays an influential role in their learning and understanding of their lessons. This showed the possibility of what and how art may be utilized in teaching science and vice versa. In terms of the profession in the medical field of the respondents, the Health Allied students recognized the significance of arts-based classroom approaches employed to their strand for their future careers,

"Mas madali kong ma-eexplain sa pasyente in an artsy way, maipapakita through visuals, especially sa mga batang pasyente," (It will be easier to explain medical conditions and terms in an artsy way to my patients, I can show them visual aids that may show a better representation for them to have a better understanding, specifically for children that I have to handle) (S2).

Additionally, the arts-related activities assigned to the students also affect their (1) intrapersonal intelligence through improving one's confidence and practices and; (2) interpersonal relationships by building one's ability to communicate with different people.

Moreover, the minority of respondents stood in a neutral position over the relevance of arts-related activities in their field; they perceived it as a break yet a distraction from academic workloads. Arts-based approaches helped some students overcome and manage their stress in their studies even though it is not directly relevant to their studies. However, sometimes, it was also the primary source of stress and anxiety for some as they perceive it as an additional subject or skill needed to their curriculum and considered existing only for art for art's sake rather than a contributor to the development of learning the students. Additionally, many respondents perceived art-related activities as irrelevant to their field of study as they considered it unnecessary and not belonging in their strand because art and science are distantly oppositional fields in terms of academic content.

Besides, Gullatt (2007) mentioned, "Americans became consumed with mathematics and science education and saw arts simply as frills" (p. 216). Unfortunately, that belief still exists today despite the voluminous research studies conducted showing the value of arts.

"Even though school officials realize the importance of educating students to become active, self-motivated learners, collaborative workers, and risk-takers (Aprill, 2001) and encouraging students to have the conviction to stand up for what they believe (Perrin 1994; Luftig 2000), they have chosen to eliminate arts." (p. 216)

If these outcomes are indeed crucial to the education of the future workforce, then arts are needed in education because of their power to develop these skills, which connects to the respondents who do not see the importance of arts in the education system.

\subsection{Challenges Encountered by the Respondents in Engaging Arts-based Instructional Approaches}

There are also different identified problems encountered by the participants with arts-related activities given to the HA Strand. The participants' common problem was the lack of skills or knowledge in the arts, with $33.33 \%$. Consequently, $14.29 \%$ struggled with time management in doing these activities, and with an equal percentage, some students do not find any problems engaging in artrelated activities. The challenges encountered by HA students were tied up in a percentage of $9.52 \%$, namely: problems in collaborative or group works, limited sources, and financial problems. Lastly, the least percentage of students, which was $4.76 \%$, struggled because of the anxiety that arts-based classroom approaches brought to the students and the difficulty of owning an original and unique style and idea in arts.

Therefore, most of the respondents struggled with their lack of skills and knowledge in the arts. Students tend to be left with no option but to do the arts-based activities assigned to them by their professors, but not all students have developed their potentials and genuinely engage in arts yet; hence, the students who have not to find the creativity within them struggles in arts-based classroom approaches because as even with their eagerness to achieve a high grade, but with them lacking the skills and knowledge, they tend to not give their hundred percent performance in it. The Health Allied students who did not experience any problem with this type of activity and personally engage in arts were aware and understand that some of their classmates deal with this problem every time there was an arts-based activity given to them. "It's okay for me, but it would be better if they lessened it 'cause we aren't focused on art. I'm already inclined in art as it is my hobby, but my classmates who aren't will have a hard time coping up." Art can be beneficial for improvement and development, but academically, some still got left behind in understanding and skills in art. Students faced difficulty in time management due to art activities taking up most of their time and leaving no room for other academic requirements for their other subjects. 
Furthermore, group work art-based activities and engagements also produced challenges. As stated earlier, some students are not artistically or musically inclined; when they engage with arts, the latter tend to perform better, which damages the nature of collaborative works. This results in unequal workload and unfair grading or scoring since a teacher assessed the group as one. To make more precise, some who are not participative enough quickly receive the same grade as those who exerted much of their time, effort, and skills into the activity.

Moreover, due to materials mainly being costly and out of the budget allowance of the students, some experienced financial problems when it comes to doing arts-based activities, e.g., the contribution for their group works, transportation for presentation practices, and other materials needed for their activities since many students in the Health Allied were not artistically inclined, they may not have the right amount of resources needed to have better materials for their work hence, requiring them to buy art materials. Lastly, anxiety and the originality factor of their works also affected the students - as with connection to the lacking of art skills, the students doubt the originality and uniqueness of their works since they still do not have and not knowledgeable about their art styles resulting in them to get anxious about their performance in this type of activities in affecting their grades. Anxiety sometimes may be out of control, affecting their performances and learning in other subjects and to them personally. Though some problems encountered in arts-based activities may be inevitable, these challenges may also push the students to enhance performativity, improve the presentation of themselves and restored behavior, understand the expressive culture and maximize their potentials that they may use in their future professions in the medical field.

In a study made by Alnajm (2020), medical professionals were required to be involved or immersed in art-based learning as it provides a broader exploration of the clinical processes through the integration of arts. Generally, arts enhance one's understanding of the world in a non-scientific way with the usage of literature in the medical field as it is considered as the first and easiest way to communicate and understand people efficiently; and with the usage of visual arts and performing arts as well as music since these are leading players in medical therapies which involve relaxation or stress prevention.

\section{Conclusion}

Because of the lack of solid appreciation and acknowledgment of the value of art in achieving quality learning, art-related programs and courses become among the least priorities of the young learners today in choosing their future careers. However, contrary to these common beliefs and practices, arts-related activities proved essential in shaping their attitude towards arts and building their interpersonal and intrapersonal intelligence, which also proved that art is innate to everyone regardless of course and strand they partake in. Despite different arguments about the role and impact of arts in learning acquisition, this study has proven that teachers highly employed arts in their instructions to meet competencies.

These approaches include graphics and designs that are materialized through brochures, infographics, and posters. Additionally, performing arts like theatre arts, role-playing or group dramatization, and visual arts are also among the bucket lists of teachers' classroom practices in successfully executing healthrelated topics that help learners organize their thoughts and analyze a particular topic and its essence differently.

Additionally, HA students' encounters with artsbased approaches helped them absorb more concepts in their field. This approach is functional as arts serve to effectively and efficiently learn ideas and properly visualize anatomical and biological compositions and arrangements. Incorporating arts with the education system integrates creativity and innovation for future medical professionals. Hence, art-based instructional approaches positively impacted the respondents' learning, especially if they were given controllably and appropriately. Arts may be distant from health and medical science, but they enrich students' learning and capabilities.

Nevertheless, still, some tend to overlook the purpose of arts in learning advancement. Likewise, arts-based classroom approaches are relevant and vital to learning regardless of their difference to sciences in terms of content - as long as it is connected to their lessons, arts may still be utilized to enrich and enhance the quality of education. Although most of the HA students recognized the importance of artsbased classroom approaches, it is undeniable that most of them experienced problems. Lacking skills and knowledge in arts challenged the students the most as they tend to not exert their hundred percent in the activities even with the eagerness to perform well; thus, resulting on creating other problems such as group work issues, anxiety, difficulty in finding own originality, limited resources, and financial problems.

Additionally, students struggled with time management because arts-related activities consume most of their time, leaving no room for other requirements. With the study results, the researchers believe that the integration of arts as classroom instructional tools and approaches be acknowledged in designing curriculum and lessons to deliver the target learning goals and competencies excellently. The results open implications to pedagogical success and advancement across disciplines. 


\section{References}

Alnajm, A.L. (2020). Arts in medicine. The Islamic University College Journal, 2(58), 93-105.

Art in Action (2021). Why is arts education important for 21st-century learning? 5 reasons to go from STEM to STEAM. https://artinaction.org/resource/arts-educationimportant-21st-century-learning-5-reasons-gostem-steam/.

Bhandari, P. (30 July 2020). An introduction to qualitative research. Retrieved from https://www.scribbr.com/methodology/qualitative -research/.

Burton, J., Horowitz, R., Abeles, H. (2000). Learning in and Through the Arts: The Question of Transfer. Studies in Art Education, 4(3), 228-258.

Cabanac, A.J., Perlovsky, L., Bonniot-Cabanac, M.C. \& Cabanac de Lafregeyre, M. (2013). Music and academic performance. Behavioural Brain Research. 244, 9-14 doi: 256.10.1016/j.br .2013.08.023.

Carter, C. (2004). Effects of formal dance training and education on student performance, perceived wellness, and self-concept in high school students. [Doctoral dissertation, University of Florida]. https://ufdc.ufl.edu/UFE0006669/00001.

Cavanaugh, J. R. (2015). Performativity. Oxford University Press.

De la Croix, A., Rose, C., Wildig, E., \& Willson, S. (2011). Arts-based learning in medical education: the students' perspective. Medical education, 45(11), 1090-1100.

Department of Education, Republic of the Philippines (n.d.). What is $K$ to 12 Program? Retrieved from https://www.officialgazette.gov.ph/k-12/.

Elpus, K. (2013). Arts education and positive youth development: Cognitive, behavioral, and social outcomes of adolescents who study the arts. University of Maryland.

Gardner, H. (1983). Howard Gardner's theory of multiple intelligences. North Illinois University.

Gibson, M. A, \& Larson, M. A. (2007). Visual arts and academic achievement. Journal for Learning through the Arts, 3(1), 8-23. 10.21977/D93110057.

Gullatt, D. E. (2007). Research links the arts with student academic gains. The Educational Forum, 71, 211-220.

Henry, T. C. (2011). The effects of high school performing arts participation on educational and occupational attainment. [Doctoral dissertation, Mississippi State]. https://ir.library.msstate.edu/ bitstream/handle/11668/15470/etd-07062011143456.pdf? sequence $=1$ \&isAllowed $=\mathrm{y}$.

Inoa, R. et al. (2014). A study on the relationship between theater arts and student literacy and Mathematics achievement. Journal for Learning through the Arts, 10(1).

Kariuki, P., \& Black, L. (2016, November 4-6). The Effects of Integrating Theatre-Arts Strategies and Traditional Strategies on Student Performance in an English Classroom at a Selected High School [Paper presentation]. Annual Conference of the Mid-South Educational Research Association, Mobile, Alabama. https://files.eric.ed.gov/fulltext /ED572006.pdf.

Khan, S. (2014). Qualitative Research MethodPhenomenology. Asian Social Science, 10(21). 10.5539/ass.v10n21p298.

MacLean, P. (2007). Use of the arts in medical and health professional education. University of Alberta Health Sciences Journal, 4(1), 26-29.

Mahgoub, Y. (2015). The importance of the development of art education curriculum in the Sudanese educational institutions. International Journal of Humanities and Social Science, 5(8), 99-104.

Marshall, J. (2014). Transdisciplinarity and art integration: Toward a new understanding of artbased learning across the curriculum. Studies in Art Education: A Journal of Issues and Research, 55(2), 104-127.

Ruppert, S.S. (2006). Critical Evidence: How the Arts Benefit the Student Achievement. National Assembly of State Arts Agencies.

Pelowski, M., Leder, H., \& Tinio, P. (2017). Creativity in the Visual Arts. In J. Kaufman, V. Glăveanu, \& J. Baer (Eds.), The Cambridge Handbook of Creativity across Domains (Cambridge Handbooks in Psychology, pp. 80109). Cambridge: Cambridge University Press. doi:10.1017/9781316274385.006.

Punzalan, J. (2018). The impact of visual arts in students' academic performance. International Journal of Education and Research, 6(7), 121130.

Schechner, R. (2003). Performance theory. Routledge.

Sandelowski, M. (2001). Real qualitative researchers do not count: The use of numbers in qualitative research. Research in Nursing \& Health, 24, 230-240. doi: 10.1002/nur.1025.

Scripp, L. (2002). An overview of research on music and learning. In R.J. Deasy's Critical Links: Learning in the Arts and Student Academic and Social Development. Educational Resources 
Information Center (ERIC), 132-136. Singg, S. \& Mull, C. (2017). Effect of color on information retention by young men and women. Juniper Online Journal of Case Studies. 2.10.19080/JOJCS.2017.02.555591.

Swapp, N. (2016 October 4). Creativity and academics: The power of an arts education. Edutopia, George Lucas Educational Foundation. https://www.edutopia.org/blog/creativityacademics-power-of-arts-education-neil-swapp.

Thomas, T. (2011). The Impact of Musical Performing Arts on the Academic Achievement of Black Males. CreateSpace Independent Publishing Platform.

Tyler, C. \& Likova, L. (2012). The role of the visual arts in enhancing the learning process. Frontiers in Human Neuroscience, 6(8). 6. 8. 10.3389/fnhum.2012.00008. 